\title{
Advancing the Scheduled Time of Hemodialysis Is Benificial for Maintenance Hemodialysis Patients with Gabapentin Intolerance
}

\author{
Jiung-Hsiun Liu ${ }^{a} \quad$ Yu-Wan Yang ${ }^{b}$ Chiu-Ching Huang ${ }^{a}$ \\ a Division of Nephrology and Kidney Institute, Department of Internal Medicine, and bepartment of Neurology, \\ China Medical University Hospital, Taichung, Taiwan, ROC
}

Gabapentin is now widely used for neuropathic pain. Recently, it was reported [1] that gabapentin is to be a therapeutic opinion in uremic pruritus, thus leading to its increased use in uremic patients. Herein, we describe an unusual case of acute paraplegia and slurred speech, which developed after a single dose of gabapentin for uremic pruritus in a hemodialysis patient. Sequential hemodialysis induced dramatically improved symptoms in this patient.

A 66-year-old female presented complaining of acute onset weakness of both the lower limbs. She underwent maintenance hemodialysis for 11 months with underlying hypertension. She suffered from refractory uremic pruritus for more than 3 months, and gabapentin $300 \mathrm{mg} 3$ times a week was prescribed following each hemodialysis session for this problem. After 4-5 h, she developed muscle weakness and slurred speech development following the first dose of gabapentin after hemodialysis. It started as an inability to stand up after squatting the following morning. The symptoms were persistent and became more serious at home. Thus, she was brought to our hospital for further investigation. The neurological examination was unremarkable except for de- creased muscle power in the lower limbs. The laboratory parameters were: serum sodium $137 \mathrm{mmol} / \mathrm{l}$, potassium $4.8 \mathrm{mmol} / 1$, total calcium $9.0 \mathrm{mg} / \mathrm{dl}$, phosphorus 3.6 $\mathrm{mg} / \mathrm{dl}$, and creatine kinase 138 IU/l (reference 38-234 IU/l in female). As a result of these findings, gabapentin intolerance was suspected in this patient. The patient underwent 4 h of hemodialysis using an Fx 80 dialyzer (Fresenius Medical Care, Germany) with a flow rate of $500 \mathrm{ml} / \mathrm{min}$ and a blood flow rate of $300 \mathrm{ml} / \mathrm{min}$. Within a 24-hour period after the hemodialysis, her muscle power returned to normal. Due to the patient's prompt recovery after hemodialysis, our findings suggested that the patient's paraplegia was more likely associated with the administration of gabapentin. The drug was withheld and the patient underwent scheduled hemodialysis over the following days.

Gabapentin is an anti-epileptic agent indicated for use in the treatment of partial seizures, but is also prescribed for uremic pruritus [1] and restless leg syndrome [2] in patients with end-stage renal disease. Gabapentin is excreted by the kidneys and its half-life is $5-7 \mathrm{~h}$ in healthy subjects. In chronic renal failure patients without dialysis, it can prolong to $132 \mathrm{~h}$. In hemodi- alysis patients, the half-life is $3.8 \mathrm{~h}$ during hemodialysis [3]. The adverse effects of gabapentin involve a variety of systems, especially the neurological system.

From this case report, we can come to two conclusions. First, gabapentin intolerance should be considered when bizarre behavior develops in hemodialysis patients after even a single dose of gabapentin. Second, hemodialysis can accelerate excretion of gabapentin; thus, the scheduled time of hemodialysis should be advanced if gabapentin intolerance or toxicity is diagnosed in hemodialysis patients.

\section{References}

1 Manenti L, Vaglio A, Borgatti PP: Gabapentin as a therapeutic option in uremic pruritus. Kidney Int 2007;72:373-377.

-2 Tan J, Derwa A, Sanu V, et al: Gabapentin in treatment of restless legs syndrome in peritoneal dialysis patients. Perit Dial Int 2006; 26:276-278.

-3 Wong MO, Eldon MA, Keane WF, et al: Disposition of gabapentin in anuric subjects on hemdilaysis. J Clin Pharmacol 1995;35:622626.

\section{KARGER}

Fax +4161306 1234 E-Mail karger@karger.ch www.karger.com
Chiu-Ching Huang, MD

Division of Nephrology and Kidney Institute, Department of Internal Medicine

China Medical University Hospital, No. 2, Yuh-Der Road

Taichung 404, Taiwan (ROC)

Tel. +886 422052121 2902, Fax +886 42203 8883, E-Mail cch659@yahoo.com.tw 